\title{
Single-Crystal Tungsten Carbide in High-Temperature In-Situ Additive Manufacturing Characterization
}

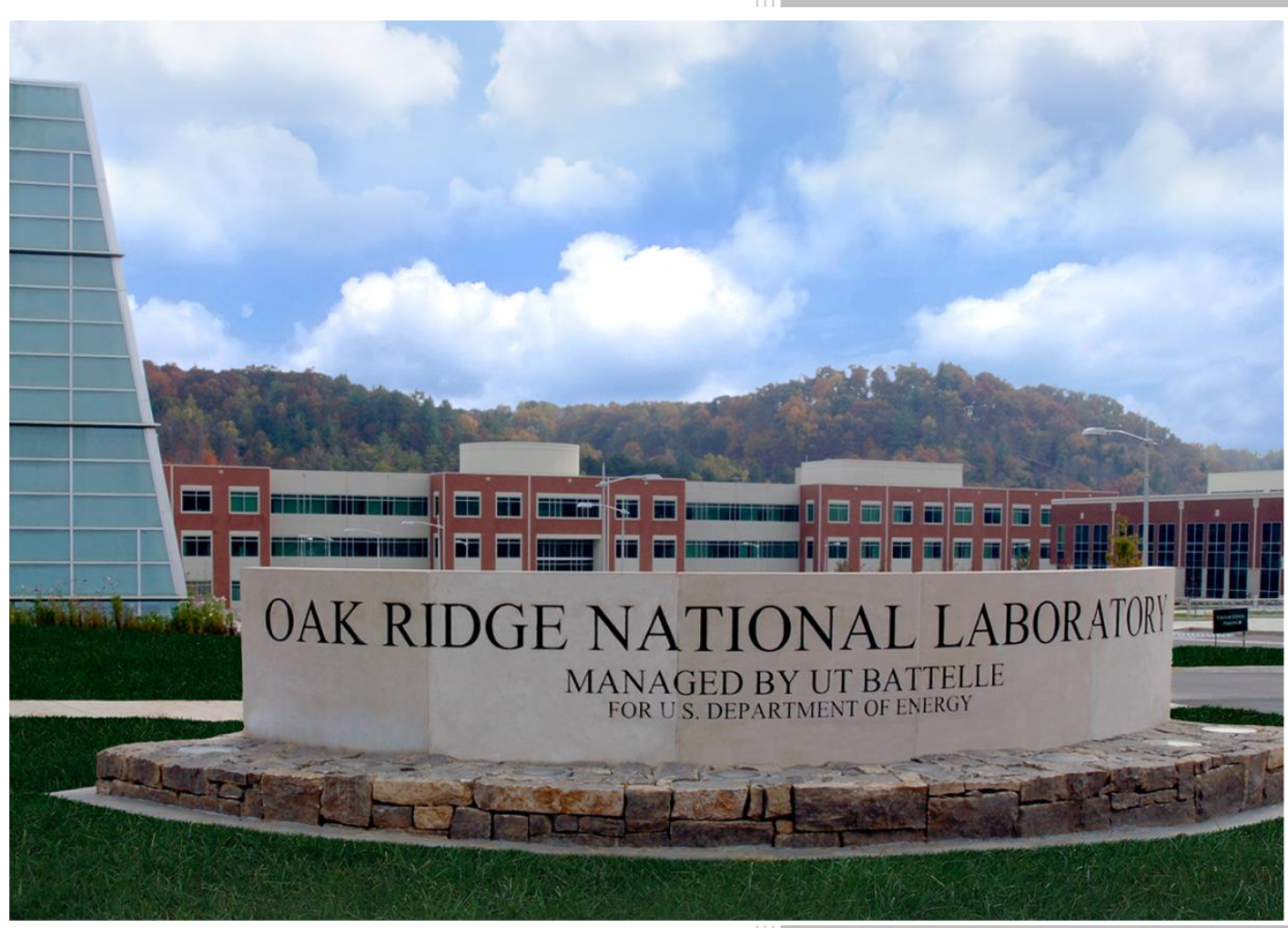

J. A. Kolopus

May 18, 2017

Approved for Public Release. Distribution is Unlimited. 


\section{DOCUMENT AVAILABILITY}

Reports produced after January 1, 1996, are generally available free via US Department of Energy (DOE) SciTech Connect.

Website http://www.osti.gov/scitech/

Reports produced before January 1, 1996, may be purchased by members of the public from the following source:

National Technical Information Service
5285 Port Royal Road
Springfield, VA 22161
Telephone 703-605-6000 (1-800-553-6847)
TDD 703-487-4639
Fax 703-605-6900
E-mail info@ntis.gov
Website http://www.ntis.gov/help/ordermethods.aspx

Reports are available to DOE employees, DOE contractors, Energy Technology Data Exchange representatives, and International Nuclear Information System representatives from the following source:

Office of Scientific and Technical Information

PO Box 62

Oak Ridge, TN 37831

Telephone 865-576-8401

Fax 865-576-5728

E-mail reports@osti.gov

Website http://www.osti.gov/contact.html

This report was prepared as an account of work sponsored by an agency of the United States Government. Neither the United States Government nor any agency thereof, nor any of their employees, makes any warranty, express or implied, or assumes any legal liability or responsibility for the accuracy, completeness, or usefulness of any information, apparatus, product, or process disclosed, or represents that its use would not infringe privately owned rights. Reference herein to any specific commercial product, process, or service by trade name, trademark, manufacturer, or otherwise, does not necessarily constitute or imply its endorsement, recommendation, or favoring by the United States Government or any agency thereof. The views and opinions of authors expressed herein do not necessarily state or reflect those of the United States Government or any agency thereof. 


\title{
Materials Science and Technology Division
} Advanced Manufacturing Office

\section{Single-Crystal Tungsten Carbide in High-Temperature In-Situ Additive Manufacturing Characterization}

\author{
Authors \\ J. A. Kolopus (ORNL) \\ L.A. Boatner (ORNL) \\ John Swindeman (Nanomechanics Inc.)
}

Date Published:

May 18, 2017

\author{
Prepared by \\ OAK RIDGE NATIONAL LABORATORY \\ Oak Ridge, Tennessee 37831-6283 \\ managed by \\ UT-BATTELLE, LLC \\ for the \\ US DEPARTMENT OF ENERGY \\ under contract DE-AC05-00OR22725
}

Approved For Public Release 


\section{CONTENTS}

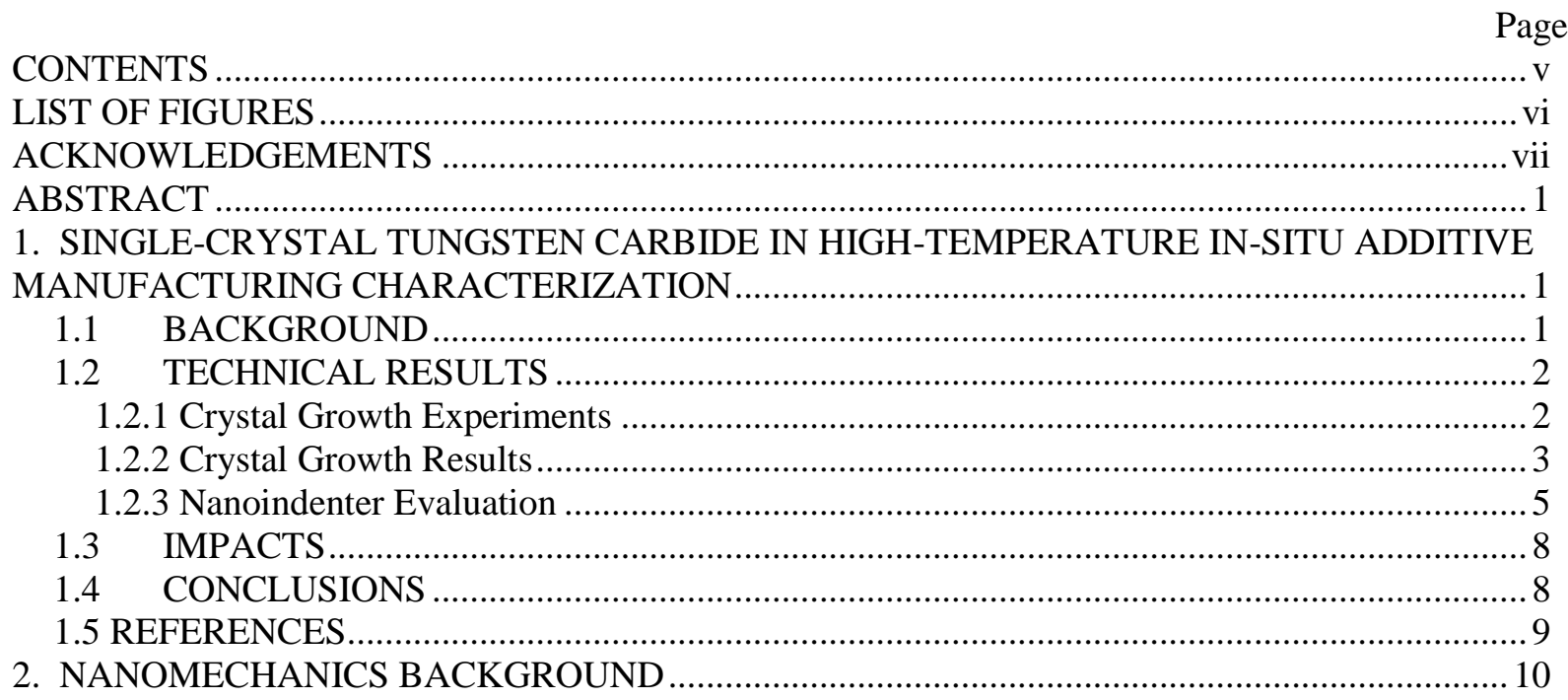




\section{LIST OF FIGURES}

Fig. 1. Growth parameters for completed crystal-growth runs ....................................................... 2

Fig. 2. Crystallographic orientation of as-grown tungsten carbide crystals....................................... 3

Fig. 3. Observed characteristics of as-grown crystals.................................................................... 3

Fig. 4. WC single crystals produced from 20 mole $\% \mathrm{WC}$ growth charge and cooled at $10^{\circ} \mathrm{C} /$ hour.

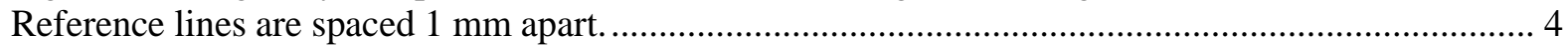

Fig. 5. A sectional view of the brazing fixture used to attach the nanoindenter shaft to the tungsten

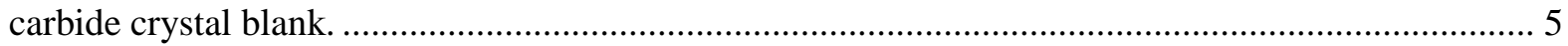

Fig. 6. Tungsten carbide crystal, before and after brazing to molybdenum indenter shaft................. 5

Fig. 7. Slotted Mo tip holder for edge mount configuration with example crystal. ............................6

Fig. 8. Mo tip holder for flat mount configuration with example c-axis aligned crystal. .....................6

Fig. 9. Example nanoindentation data on pure aluminum using the c-axis oriented $\mathrm{WC}$ tips. ................ 8 


\section{ACKNOWLEDGEMENTS}

This CRADA NFE-16-06110 was conducted as a Technical Collaboration project within the Oak Ridge National Laboratory (ORNL) Manufacturing Demonstration Facility (MDF) sponsored by the US Department of Energy Advanced Manufacturing Office (CPS Agreement Number 24761).

Opportunities for MDF technical collaborations are listed in the announcement "Manufacturing Demonstration Facility Technology Collaborations for US Manufacturers in Advanced Manufacturing and Materials Technologies" posted at http://web.ornl.gov/sci/manufacturing/docs/FBO-ORNL-MDF-2013-2.pdf. The goal of technical collaborations is to engage industry partners to participate in short-term, collaborative projects within the Manufacturing Demonstration Facility (MDF) to assess applicability and of new energy efficient manufacturing technologies. Research sponsored by the U.S. Department of Energy, Office of Energy Efficiency and Renewable Energy, Advanced Manufacturing Office, under contract DE-AC0500OR22725 with UT-Battelle, LLC. 


\begin{abstract}
Nanoindenters are commonly used for measuring the mechanical properties of a wide variety of materials with both industrial and scientific applications. Typically, these instruments employ an indenter made of a material of suitable hardness bonded to an appropriate shaft or holder to create an indentation on the material being tested. While a variety of materials may be employed for the indenter, diamond and boron carbide are by far the most common materials used due to their hardness and other desirable properties. However, as the increasing complexity of new materials demands a broader range of testing capabilities, conventional indenter materials exhibit significant performance limitations. Among these are the inability of diamond indenters to perform in-situ measurements at temperatures above $600^{\circ} \mathrm{C}$ in air due to oxidation of the diamond material and subsequent degradation of the indenter's mechanical properties. Similarly, boron carbide also fails at high temperature due to fracture. [1] Transition metal carbides possess a combination of hardness and mechanical properties at high temperatures that offer an attractive alternative to conventional indenter materials. Here we describe the technical aspects for the growth of single-crystal tungsten carbide (WC) for use as a high-temperature indenter material, and we examine a possible approach to brazing these crystals to a suitable mount for grinding and attachment to the indenter instrument. The fabrication and characterization of indenters produced with this material under ambient conditions likely to be encountered during in-situ testing, and comparisons with existing commercial indenter materials are examined. Results of material testing performed with WC indenters are also compared to values presented in existing literature for the materials being examined.
\end{abstract}

\title{
1. SINGLE-CRYSTAL TUNGSTEN CARBIDE IN HIGH-TEMPERATURE IN-SITU ADDITIVE MANUFACTURING CHARACTERIZATION
}

This phase one technical collaboration project (MDF-TC-2016-87) was begun on March 30, 2016 and was completed on March 30, 2017. The collaboration partner Nanomechanics Inc. is a small business. The project investigated use of single-crystal tungsten carbide (WC) for use as a hightemperature indenter material with the potential for in-situ measurement for additive manufacturing.

\subsection{BACKGROUND}

Despite the rapid rate of advances in additive manufacturing technology, the capability of in-situ materials testing and measurement instruments under ambient conditions remains limited and represents a significant challenge particularly in the area of process monitoring in a high- temperature environment.[2] Nanomechanics Inc. is an Oak Ridge, Tennessee-based company that designs and manufactures advanced materials testing systems and instruments for characterizing the mechanical properties of a wide range of materials used in manufacturing and scientific research. To facilitate the development of a suitable high-temperature indenter material, a Cooperative Research and Development Agreement (CRADA) was entered into between Nanomechanics Inc. and Oak Ridge National Laboratory in March 2016. Under the terms of the CRADA, ORNL researchers conducted a series of crystal growth runs to investigate the synthesis of single-crystal tungsten carbide crystals for use as a high-temperature indenter material. The crystals produced were then submitted to Nanomechanics Inc. personnel for characterization and testing. 


\subsection{TECHNICAL RESULTS}

This section summarizes the WC crystal-growth and recovery process and the preliminary investigation into possible methods for the brazing / bonding of the crystal material to the indenter shaft.

\subsubsection{Crystal Growth Experiments}

Single crystals of tungsten carbide were grown using a molten metal flux technique. The starting growth charge consisted of tungsten carbide powder (Kennemetal \#SCNC022) and cobalt powder (Sigma-Aldrich \#266647). Cobalt metal was chosen as the flux due to its ability to dissolve higher amounts of $\mathrm{WC}$ at lower temperatures [3] and its solubility in $\mathrm{HCl}$ to facilitate the crystal recovery process. A total of 8 growth runs were prepared by weighing out the powders into 100 gram batches with WC concentrations of 15,20 , and 30 mole \%. Individual charges were placed into a covered 50$\mathrm{ml}$ alumina crucible and heated in an Astro - type graphite element electric resistance furnace under a flowing argon atmosphere. The charges were held at high temperature for a period sufficient to ensure homogeneity, cooled at variable rates to a point below the crystallization temperature, and then rapidly cooled to room temperature. The resulting solidified ingot measured approximately $30 \mathrm{~mm}$ in diameter, $10 \mathrm{~mm}$ in thickness and contained WC single crystals embedded in a cobalt matrix. A summary of the growth parameters is given in fig. 1.

\begin{tabular}{|c|c|c|c|c|}
\hline $\begin{array}{c}\text { Run } \\
\text { Number }\end{array}$ & Mol \% WC & Melt Temp. & Dwell Time & Cooling Rate \\
\hline 042016 & 20 & $1650^{\circ} \mathrm{C}$ & 1 hour & $20^{\circ} \mathrm{C} /$ Hour \\
\hline 042216 & 20 & $1650^{\circ} \mathrm{C}$ & 1 hour & $10^{\circ} \mathrm{C} /$ Hour \\
\hline 042616 & 20 & $1650^{\circ} \mathrm{C}$ & 1 hour & $5^{\circ} \mathrm{C} /$ Hour \\
\hline 050616 & 30 & $1650^{\circ} \mathrm{C}$ & 1 hour & $10^{\circ} \mathrm{C} /$ Hour \\
\hline 051116 & 30 & $1750^{\circ} \mathrm{C}$ & 8 hour & $10^{\circ} \mathrm{C} /$ Hour \\
\hline 052416 & 15 & $1650^{\circ} \mathrm{C}$ & 4 hour & $10^{\circ} \mathrm{C} /$ Hour \\
\hline 060316 & 15 & $1650^{\circ} \mathrm{C}$ & 4 hour & $5^{\circ} \mathrm{C} /$ Hour \\
\hline 091616 & 20 & $1650^{\circ} \mathrm{C}$ & 8 hour & $10^{\circ} \mathrm{C} /$ Hour \\
\hline
\end{tabular}

Fig. 1. Growth parameters for completed crystal-growth runs

Following removal from the crucible, the cobalt ingot was placed in $150 \mathrm{ml}$ of boiling $\mathrm{HCl}$ to dissolve the cobalt binder and release the WC crystals. The acid solution was replaced every 24 hours, and the cobalt metal completely dissolved in about 5 days. The WC crystals were then recovered for characterization.

The reaction of the acid with the cobalt metal, given in equation 1, was observed to produce a dark blue solution characteristic of anhydrous cobalt (II) chloride. ${ }^{[4]}$

$$
\mathrm{Co}+2 \mathrm{HCl} \rightarrow \mathrm{CoCl}_{2}+\mathrm{H}_{2}
$$

Initially, this solution was allowed to crystalize and well-formed hexagonal crystals of the salt were recovered. Cobalt chloride in both the anhydrous and hexahydrate form has multiple commercial uses, ${ }^{[5]}$ and the recovery of this potentially valuable commercial product may be desirable under production conditions. However, as this was outside the scope of the present work, and the volume of solution produced was small, the $\mathrm{CoCl}_{2}$ solution was subsequently disposed of as a waste product. 


\subsubsection{Crystal Growth Results}

Well-formed triangular and irregular hexagonal plates of single-crystal WC were produced by the above described method. It was observed that crystal size and quality correlated well with WC concentration and cooling rates as previously reported in literature, $[3,6]$ with higher concentrations of WC producing a greater number of smaller crystals, while lower concentrations produced fewer but larger crystals. It was also observed that slower cooling rates tended to produce larger crystals, but these crystals exhibited a greater number of defects and produced a greater number of polycrystalline clusters. The crystals produced displayed a preferential growth orientation with the caxis perpendicular to the face of the crystal and the edges parallel to the $\{1100\}$ planes. (fig. 2) The average sizes and observed characteristics of the crystals produced are given in fig. 3 and illustrated in fig. 4.

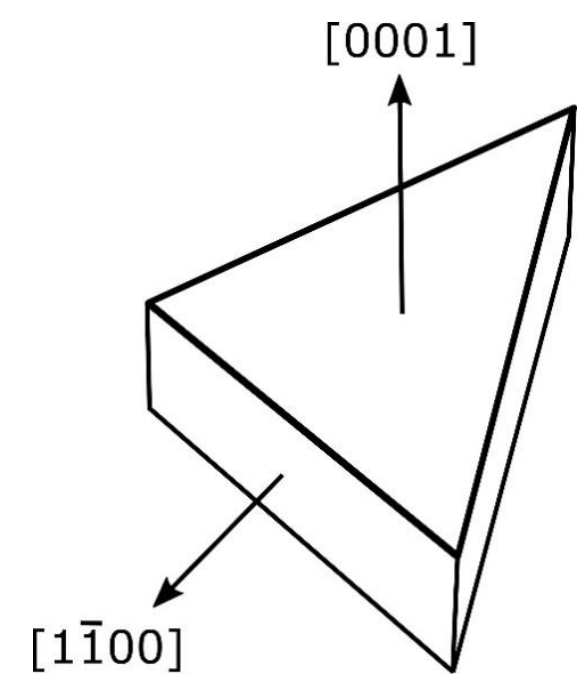

Fig. 2. Crystallographic orientation of as-grown tungsten carbide crystals.

\begin{tabular}{|l|l|l|l|l|}
\hline $\begin{array}{l}\text { Mol } \\
\text { \% }\end{array}$ & $\begin{array}{l}\text { Cooling } \\
\text { Rate }\end{array}$ & $\begin{array}{l}\text { Avg. } \\
\text { Thickness }\end{array}$ & $\begin{array}{l}\text { Avg. } \\
\text { Width }\end{array}$ & Observations \\
\hline 15 & $5^{\circ} \mathrm{C} /$ hour & $1.5 \mathrm{~mm}$ & $6-7 \mathrm{~mm}$ & Greater number of polycrystals \\
\hline 15 & $10^{\circ} \mathrm{C} /$ hour & $1.3 \mathrm{~mm}$ & $5-6 \mathrm{~mm}$ & Triangular shape \\
\hline 20 & $5^{\circ} \mathrm{C} /$ hour & $1.1 \mathrm{~mm}$ & $4 \mathrm{~mm}$ & Good size distribution \\
\hline 20 & $10^{\circ} \mathrm{C} /$ hour & $0.9 \mathrm{~mm}$ & $3 \mathrm{~mm}$ & Good yield of well-formed crystals \\
\hline 20 & $20^{\circ} \mathrm{C} /$ hour & $0.7 \mathrm{~mm}$ & $2-3 \mathrm{~mm}$ & Well - formed crystals, too thin for use. \\
\hline 30 & $10^{\circ} \mathrm{C} /$ hour & $0.3 \mathrm{~mm}$ & $1 \mathrm{~mm}$ & Crystals too small for use \\
\hline
\end{tabular}

Fig. 3. Observed characteristics of as-grown crystals. 


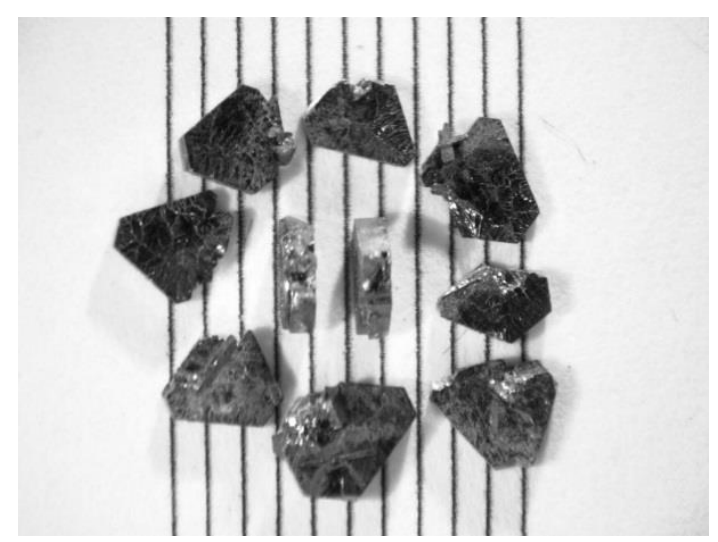

Fig. 4. WC single crystals produced from 20 mole $\%$ WC growth charge and cooled at $10^{\circ} \mathrm{C} /$ hour. Reference lines are spaced $1 \mathrm{~mm}$ apart.

Various transition metal carbides exhibit hardness values that exceed that of $\mathrm{WC}$ at room temperature. Among these are titanium carbide with a measured hardness of $3000 \mathrm{~kg} / \mathrm{mm}^{2}$. However, at temperatures above $400^{\circ} \mathrm{C}$, only WC retains its high hardness characteristics. ${ }^{[7]}$ The hardness of tungsten carbide single crystals is dependent on the crystallographic orientation with the (0001) face displaying the highest measured hardness at $2100 \mathrm{Kg} / \mathrm{mm}^{2}$ at room temperature. ${ }^{[8]}$ Information furnished by Nanomechanics Inc. indicated that crystals with an axial orientation perpendicular to the (0001) plane and measuring slightly larger than $1 \mathrm{~mm}$ x $1 \mathrm{~mm} \times 1 \mathrm{~mm}$ would be desirable for fabrication of high-temperature indenters. The observed results of our growth activities indicate that a high yield of WC crystals with suitable characteristics could be produced with growth charges containing between 15 and 20 mole $\%$ of WC and cooled at a rate of approximately $10^{\circ} \mathrm{C} /$ hour. The relatively large size of the preferentially oriented crystals produced allow for the fabrication of multiple indenters from each crystal thus increasing the yield of finished indenters from each crystal growth-run and reducing the overall cost of production for each indenter.

Preliminary investigations were also conducted into possible methods of brazing or attaching the WC crystal blank to the indenter shaft for installation on the indenter instrument. Cobalt was selected as a possible brazing medium due to its hardness, resistance to oxidation, and excellent wetting characteristics. Its melting point $\left(1495^{\circ} \mathrm{C}\right)$ is significantly higher than nearly all commonly employed brazing alloys ${ }^{[9]}$ allowing its use as a binder at temperatures in excess of $1100^{\circ} \mathrm{C}$.

Molybdenum indenter shafts, furnished by Nanomechanics Inc., were placed in a two-piece insulating ceramic holder with the oriented WC crystal and cobalt powder brazing material as shown in fig. 5. The holding fixture was heated to $1600^{\circ} \mathrm{C}$ for 30 minutes in an argon atmosphere and allowed to cool to room temperature. Two brazing runs were attempted with unsatisfactory results, (fig. 6) however, observations of the brazed samples indicated that the use of cobalt foil in place of the powder would likely result in a higher quality weld with greater strength. Additional investigations into the attachment of the WC blanks to the indenter shafts were not made due to the limited resources remaining in the CRADA. 


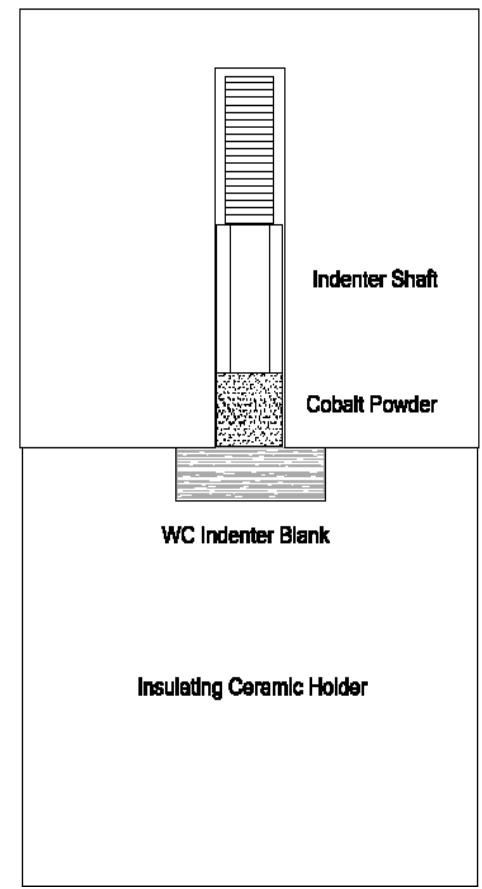

Fig. 5. A sectional view of the brazing fixture used to attach the nanoindenter shaft to the tungsten carbide crystal blank.

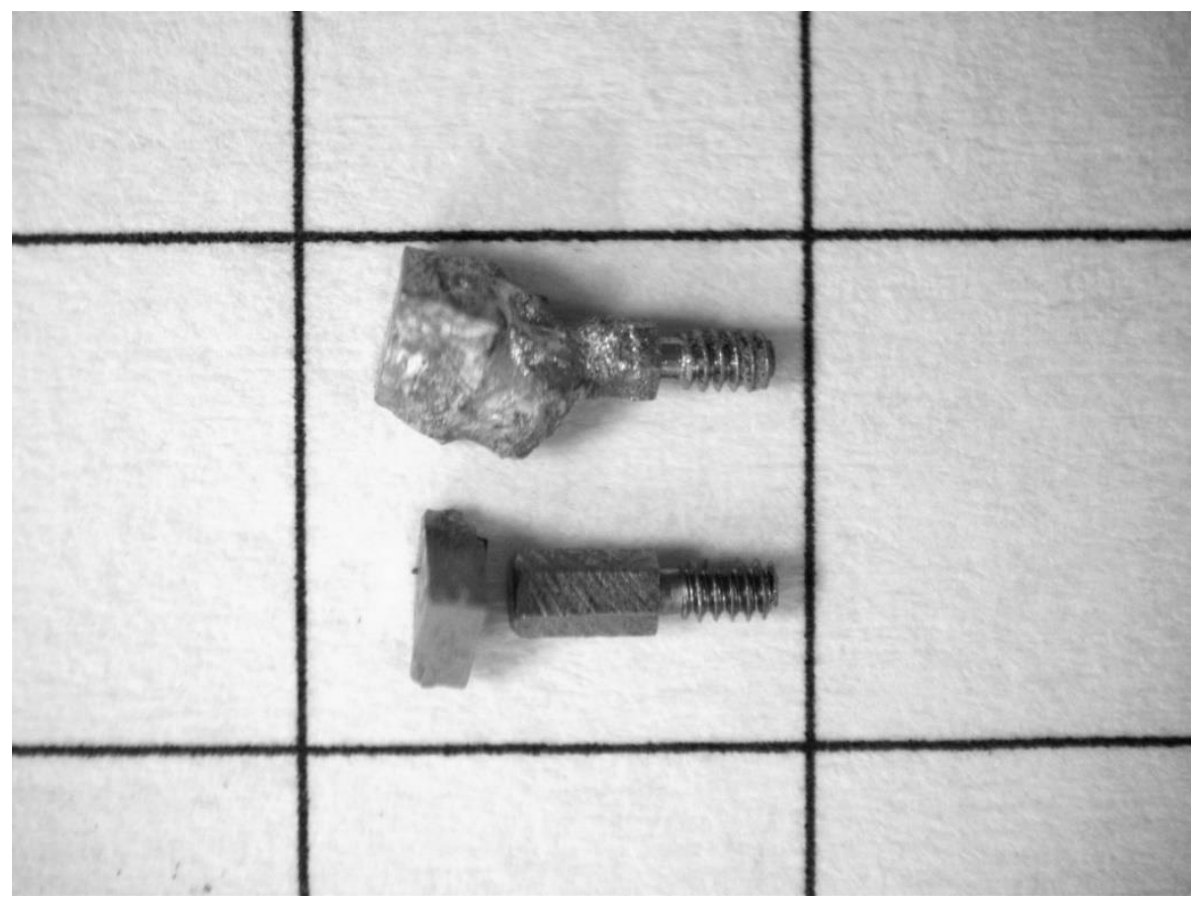

Fig. 6. Tungsten carbide crystal, before and after brazing to molybdenum indenter shaft.

\subsubsection{Nanoindenter Evaluation}

Nanomechanics developed molybdenum tip holders for use with the WC crystals provided by 
ORNL. Several designs were considered, and prototypes constructed, for mounting the WC crystals in two primary orientations: a $\mathrm{C}$-axis orientation in which the triangular crystal was mounted parallel to the face of the tip holder, and an "edge mount" configuration in which the WC crystal was mounted perpendicular to the face.

For the edge-mount configuration (fig. 7), a slot was cut in the blank face of the Mo tip holder so that the base of the WC crystal triangle sat in the slot. For the flat-mount configuration (fig. 8), two alternatives were explored. The first was to allow the WC crystal to sit directly on the face of the tip holder. The second was to machine a recess in the tip holder and to select WC crystals of appropriate size to be located in the recess.

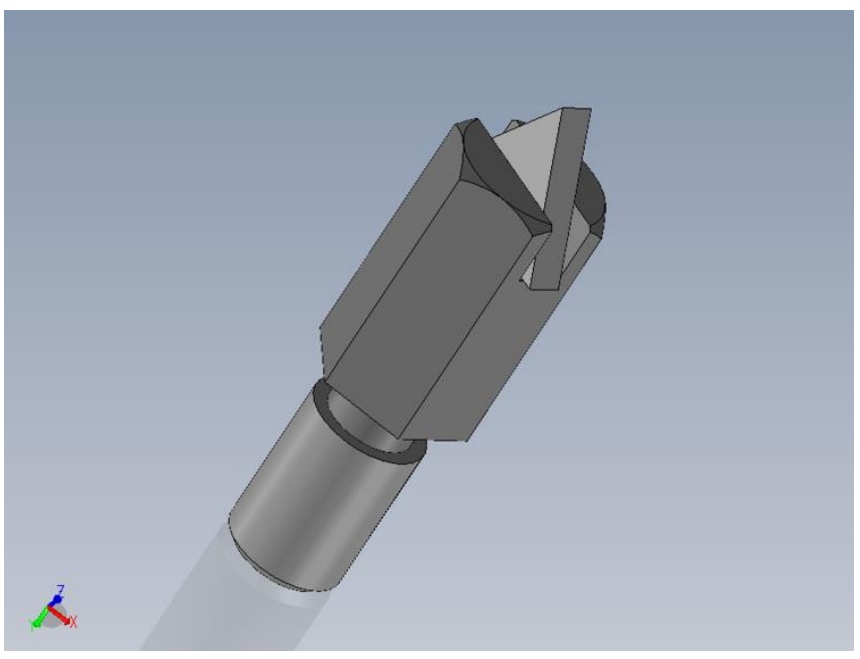

Fig. 7. Slotted Mo tip holder for edge mount configuration with example crystal.

The presumption was that the C-axis oriented crystals (flat mounted) would provide superior properties in terms of modulus of elasticity, and that the grinding process would be less likely to create fractures in this orientation.

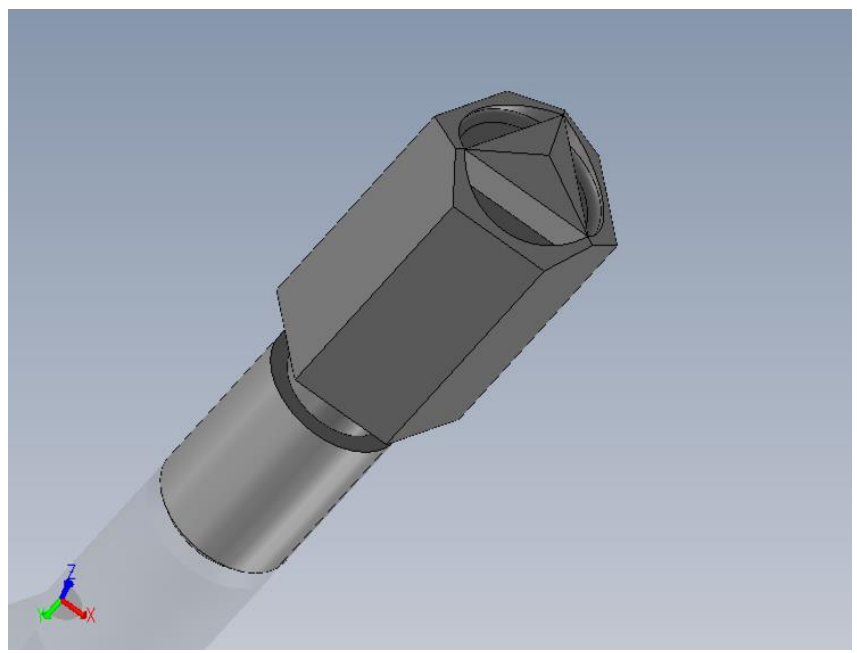

Fig. 8. Mo tip holder for flat mount configuration with example c-axis aligned crystal. 
WC crystals provided by ORNL and Mo tip holders were subjected to a proprietary braze process. From a process standpoint, the recessed flat-mounted tip assemblies were the most reproducible. The slot-mounted WC crystals had a tendency to "tilt" in the slot, resulting in an undesirable angle between the crystal and the tip holder, which leads to a non-uniaxial loading condition. The flat-mounted WC crystals without the recess moved as the braze material flowed, and misoriented the $\mathrm{C}$-axis relative to the tip holder axis.

Ultimately, several slot-mounted tips and several recessed flat-mounted tips were successfully brazed with a $1000^{\circ} \mathrm{C}$ compatible flux mixture. These tips were subsequently polished into the Berkovich diamond geometry and tested.

A second round of tips were fabricated using the recessed flat-mount method and using a braze filler metal which melted at approximately $1300^{\circ} \mathrm{C}$. These tips had not been polished and tested prior to the completion of the CRADA term.

The WC/Mo tips were repeatedly cycled to temperatures up to $1000^{\circ} \mathrm{C}$ using Nanomechanics' InSEM HT Nanoindenter. The material system demonstrated survivability - the coefficient of thermal expansion mismatches were insufficient to degrade the structure of the braze, and the initial braze survived the $1000^{\circ} \mathrm{C}$ exposure despite the proximity to the flow temperature of the braze.

The WC crystals were subjected to the same polishing operation as the traditional diamond, doped diamond, sapphire, and other common tip materials. The tip rounding of the WC tips (the degree of imperfection of the tip) was approximated to 50nm, which contrasts with the $20 \mathrm{~nm}$ rounding typically seen on diamond, and the $100 \mathrm{~nm}$ rounding typically seen on sapphire and WC-Co tips. The conclusion was that the WC tips were only a slight compromise from the diamond tips in this regard.

In room-temperature testing, the WC tips performed well in producing quality indentation data on the standard reference material fused silica $\left(\mathrm{SiO}_{2}\right)$, producing the nominal $72 \mathrm{GPa}$ expected value. The modulus correction for the single-crystal WC tips sourced from ORNL was significantly lower than for the WC-Co tips previously evaluated, indicating the superiority of the single-crystal WC to the more easily obtainable WC-Co.

The WC crystals proved particularly brittle and susceptible to damage in impact and nonuniaxial experiments. It was found that the sharpened part of the crystal could be easily sheared off, and that impact tests on $\mathrm{SiO}_{2}$ shattered the crystal. Consequently, the WC tips are not suitable for scratch or adhesion tests in which the sample is translated laterally to the tip.

Further, as WC has reactivity in some material systems at temperature, while the tip material is a good general high-temperature alternative to diamond, development of alternative high-strength materials is of continuing interest.

Finally, indentation testing was performed using the WC tips on pure aluminum samples from room temperature up to $550^{\circ} \mathrm{C}$ (fig. 9). There was good agreement between the results generated in this testing and literature values for pure aluminum. 


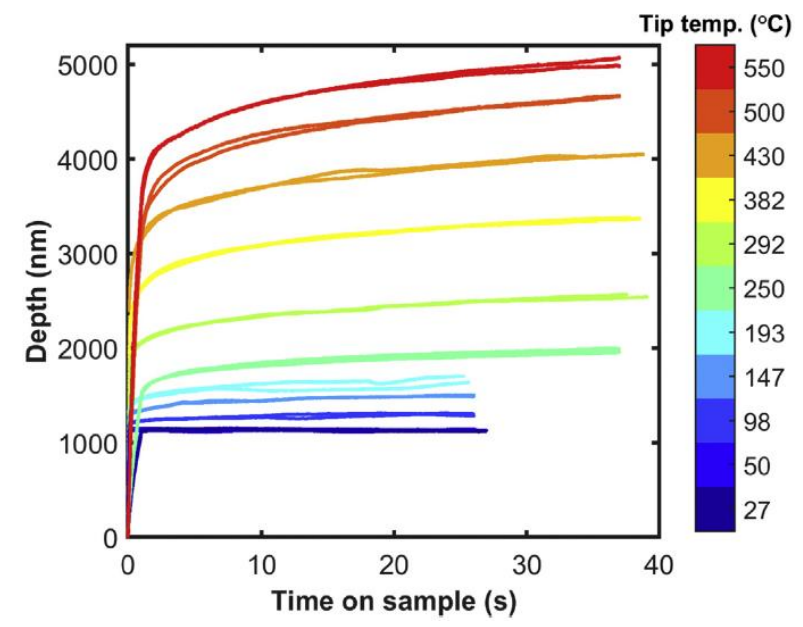

Fig. 9. Example nanoindentation data on pure aluminum using the c-axis oriented WC tips.

\subsection{IMPACTS}

This CRADA set out to find a viable and efficient path for creating single-crystal tungsten carbide nanoindentation tips for high temperature applications. The potential impact of this goal is broad and extends to many fields (e.g., automotive, aerospace, and renewable resources) because current nanoindentation tip technology, and thus the ability to characterize mechanical properties at elevated temperatures, is directly limited by materials. Single crystal tungsten carbide can provide a solution to these problems if the creation of a tip is feasible. With that objective in mind, there are specific metrics that were used to decide whether to move forward with the WC tips in the marketplace. The following metrics passed:

(1) Tip survives and retains geometry above $1000^{\circ} \mathrm{C}$.

(2) Crystal c-axis orientation results in an elastic modulus above $500 \mathrm{GPa}$.

(3) WC mounted crystal can be ground/polished with a pyramidal shape.

(4) WC tip measures an elastic modulus of $72 \mathrm{GPa}+/-10 \%$ on a fused silica reference material.

The following metrics still need clarification:

(1) WC tips are generally fracture resistant in normal nanoindentation applications.

(2) WC tips can survive $>10,000$ indents without failure.

(3) The tip elastic modulus has a standard deviation of $10 \%$ from tip to tip.

Based on the metrics above and the results, Nanomechanics, Inc. has supplied WC tips to beta testing sites in the United States. Nanomechanics, Inc. considers the outcomes and impacts of this study to be a success as material nanoindentation testing is being carried out using the technology developed in this CRADA.

\subsection{CONCLUSIONS}

Single-crystal tungsten carbide is a promising candidate for the fabrication of nanoindenter tips for high-temperature in-situ characterization of materials employed in additive manufacturing. Working in cooperation with local private industry, ORNL researchers have successfully demonstrated an economical process to produce high-quality tungsten carbide crystalline material and 
explored potential methods for the fabrication of the high-temperature indenters. Characterization of Nanomechanics Inc. fabricated indenters using ORNL grown WC material demonstrated survivability through repeated high-temperature cycling and produced results consistent with established values during in-situ testing on pure aluminum samples over a range of ambient temperature conditions. The work performed in this CRADA presents several opportunities for future collaborative efforts aimed at refining the crystal-growth process, conducting greater characterization of the crystal material performance under a wider range of operating conditions, and the development of a high-strength brazing method to facilitate the fabrication of the nanoindenters. Additional research into the properties and characteristics of other high-hardness materials at elevated temperatures also warrants consideration to keep pace with the rapid pace of technological achievement in the area of additive manufacturing.

\subsection{REFERENCES}

[1] Kohlstedt D. L., Journal of Material Science 8 (1973) 777-786

[2] Everton S. K. et al. Materials \& Design 95 (2016) 431-445

[3] A. P. Gerk and J.J. Gilman. Journal of Applied Physics 39, 10 (1968)

[4] Howell O. R., Journal of the Chemical Society, 1927, 158-170

[5] CRC Handbook of Chemistry \& Physics, pg. 4-10

[6] A. P. Gerk. "The Growth of Tungsten Carbide Monocrystals." Thesis submitted by A. P . Gerk, Univ. of Illinois, February 1968.

[7] Toth L. ed. "Transition Metal Carbides and Nitrides.” Academic Press, New York 1971

[8] Takahashi T. and Freise E.J., The Philosophical Magazine 12 (1965) 1-8

[9] Jacobson D.M., Humpston G., "Principles of Brazing", ASM International, Materials Park, Ohio (2005) 


\section{NANOMECHANICS BACKGROUND}

Nanomechanics, Inc. designs and produces instrumentation for the mechanical characterization of materials at the micro and nano-scales. Our staff includes the inventor of the Nano Indenter, a tool widely used for obtaining material properties on a wide range of materials and devices.

Nanomechanics specializes in industrial-quality nanoindenters, in-situ nanomechanical testing equipment, and high-temperature nanomechanical test equipment. 